\title{
Parents' and children's communication about genetic risk: a qualitative study, learning from families' experiences
}

\author{
Alison Metcalfe ${ }^{\star, 1}$, Gill Plumridge ${ }^{2}$, Jane Coad ${ }^{3}$, Andrew Shanks² and Paramjit Gill ${ }^{2}$ \\ Little is known about how parents explain to their children their risk of inheriting a gene that may cause disease in the child or \\ in the child's future progeny. This study explored how genetic risk information is shared between family members and the factors \\ affecting it, to ascertain the implications for children, young people and their parents to inform future service development and \\ provision. A volunteer group of parents, children (8-11 years) and young people (12+ years) in families affected by or at risk of \\ one of six inherited genetic conditions was interviewed. The semi-structured interviews explored the roles of family members, \\ the language used and the self-reported psychological outcomes in a discussion on genetic risk information. The findings were \\ analysed using grounded theory. A total of 33 families participated, which included 79 individuals. Parents often found \\ discussing genetic risk information very difficult and emotionally painful. Discussions were not usually planned and often a \\ major event prompted parents to finally explain genetic risks to their children; however, children usually preferred to learn about \\ the genetic condition gradually throughout childhood. Parents identified a number of challenges they faced related to talking to \\ children, and many thought health professionals should provide more advice to assist them in providing developmentally \\ appropriate information. We therefore conclude that greater emphasis is required in supporting parents and children in \\ discussing genetic risk information throughout their child's development. Open communication about genetic risks throughout \\ childhood seemed to help children and parents cope better and come to terms with the implications of the genetic condition. \\ European Journal of Human Genetics (2011) 19, 640-646; doi:10.1038/ejhg.2010.258; published online 16 February 2011
}

Keywords: risk communication; family; children; parent; coping

\section{INTRODUCTION}

In families affected by genetic conditions, parents not only have the challenge of explaining the illness, its treatment and outcomes but they also have the concomitant stressor of discussing the inherited nature of the condition with their children. Many parents struggle to know when, how and what to tell their children about the genetic risk because they fear causing distress and so feel a need to protect their children from this information. ${ }^{1-5}$ Many parents also describe a large burden of guilt, which can contribute to their reticence in discussing genetic conditions with their family. ${ }^{4}$ However, previous studies have shown that withholding genetic risk information from children until they are adults can affect their coping, self-esteem ${ }^{6,7}$ reproductive decision making ${ }^{4,7}$ and family cohesion. ${ }^{8,9}$

Studies examining families' communication of genetic risk information between children and their parents, which involves the perspectives of all members, including those of affected and unaffected children, have to date been limited. With regard to children and genetic risk, the focus of debate has centred on genetic testing and the best time to carry it out rather than how to help families cope and come to terms with the condition and its risk. Many health professionals report being asked for advice on talking to children (personal communications). However, little is known about the children's understanding and experiences of learning about inherited genetic risk within their families. Studies to date are small, ${ }^{10}$ limited to a single condition and have rarely included all family members, affected and unaffected individuals and those at risk of carrying the affected gene. Differences related to patterns of inheritance, age at onset, morbidity and mortality, where parents have to discuss the genetic condition with their children at contrasting stages of their development, have not been examined.

To address these gaps, this study explored the communication with regard to genetic risk and the factors that affect it with all family members. Six different genetic conditions were chosen, which encompassed different morbidity and mortality patterns in relation to the more common Mendelian inheritance patterns. The aim was to draw on a breadth of families' experiences to ascertain what information children require at different stages of their childhood, how to provide it and their likely reactions to genetic risk information according to morbidity and mortality outcomes of the genetic condition.

\section{METHODS}

Theoretical framework

Family communication about genetic risk was investigated qualitatively from the perspective of three interrelated models. These focused on the roles of

${ }^{1}$ Florence Nightingale School of Nursing and Midwifery King's College London, London, UK; ${ }^{2}$ School of Health \& Population Science, Primary Care Clinical Sciences, University of Birmingham, Edgbaston, Birmingham, UK and ${ }^{3}$ Faculty of Health \& Life Sciences, Coventry University, Coventry, UK

*Correspondence: Professor A Metcalfe, Florence Nightingale School of Nursing and Midwifery King's College London, James Clerk Maxwell Building 57, Waterloo Road, London SW1 8WA, UK.

Tel: +020 7848 3828; E-mail: alison.metcalfe@kcl.ac.uk

Received 15 July 2010; revised 25 November 2010; accepted 1 December 2010; published online 16 February 2011 
family members and influential factors (family system theory ${ }^{11}$ ), what was communicated and the language used (drawing on the symbolic interaction theory $^{12}$ ) and the behavioural outcomes ${ }^{13}$ of children and parents. Each model informed the design of the interview schedule and was used as part of the grounded theory development for the data analysis. Before commencing the study a psycho-social definition of family ${ }^{10}$ was established.

An advisory group of six parents and five young people from diverse cultural and social backgrounds was consulted about the conduct of the study and later on the credibility of the findings. The group discussed the findings in context and contributed to the development of subsequent recommendations. The study was approved by the Liverpool Children's Research Ethics Committee (REC No:07/Q1502/16).

\section{Participant families}

Potential participant families were volunteers identified through charity and NHS support groups in England and Wales. Parents and their children (irrespective of their risk status: affected, at risk or unaffected) from families affected by one of six genetic conditions were invited to participate on the basis of the inclusion criteria. It was anticipated that six to seven families would be recruited for each condition (Table 1). The genetic conditions were chosen not only because they have a distinct pattern of inheritance and vary in age at onset but also because genetic testing may take place at different ages; some diseases caused are life-limiting and there are different impacts on the individual in terms of illness duration.

\section{Data collection}

Semi-structured interviews were conducted with parents, children (8-12 years), young people (13-17 years) and adults (18+ years). Children were interviewed independently of their parents or siblings. Consent was obtained to audiorecord interviews in all cases except one.

Interview schedules were developed from the literature review and from discussion with the advisory and steering groups. The interviews used neutral, open-ended questions, and interviewers were responsive in adapting their questions, language style and question order according to the responses received. The questions focused on the roles of family members in discussing the genetic condition and its risk, the language used and the behavioural outcomes in terms of emotional response, coping and adaptability. For children, art-based portfolios were developed for use before interviews ${ }^{14}$ to provide a sense of control in the activity and assist with establishing a rapport and an environment conducive to the discussion of personal and sensitive information. ${ }^{15,16}$

\section{Data analysis}

Interviews were transcribed verbatim and analysed using social constructivist grounded theory. ${ }^{17}$ Because of the large quantity of data collected, two analysis frameworks, one for children and the other for adults, were developed using interviews from five families affected by different genetic conditions. The two frameworks kept the children's perspective clearly separated from that of adults at this stage.

Transcripts and field notes were read for each interview. Two researchers developed each framework, initially working independently to identify phenomena within the interview and develop concepts and a list of categories before agreeing on an overall list for the framework with the second researcher. As part of developing the framework, the concepts were also considered in terms of family communication models; for example, roles of family members in communication, and self-reporting of behavioural outcomes by children and adults. Each category had clearly defined properties and dimensions for the concepts that informed its development. Once developed, each framework was rechecked for reliability and applicability against the first five interviews, plus an additional two families' interviews chosen randomly.

The framework underwent modification to incorporate new phenomena and concepts as they emerged, and interviews previously analysed were revisited to ascertain whether similar phenomena had been overlooked. Data were coded into the framework using the software package NVIVO-7. Each family's transcripts and field notes were grouped together to explore the level of agreement between parent(s) and children, including the following: how
Table 1 Explanation of the genetic condition and inclusion criteria used to recruit participants

Genetic Condition and summary of

inheritance pattern

Inclusion criteria

- Cystic fibrosis (CF) (autosoma recessive - onset from birth)

- Neurofibromatosis (NF) (autosomal dominant - onset from birth, wide variation in signs and symptoms)

- Duchenne Muscular Dystrophy (DMD) (X-linked recessive - onset of symptoms in early childhood progressive deterioration until death in late adolescence early adulthood)

- Haemoglobinopathies $(\mathrm{HbO})$ (autosomal recessive - acute episodes throughout child and adulthood, vary in frequency)

- Familial Adenomatous Polyposis(FAP) (autosomal dominant - adolescence onset)

- Huntingtons Disease (HD) (autosomal dominant - usually adult onset, often middle age)

- Participant families had been diagnosed with or at risk from the genetic condition for a minimum of 12 months, and at least one member (either child or adult) was affected or at risk from the condition, including the possibility of being a carrier.

- The family had access to a peer support group or a health professional following the interview so that any personal or family issues unintentionally triggered by the interviewers could be discussed with experienced people capable of giving appropriate support and advice.

- The research ethics committee directed that the children to be interviewed should be aged 8 years and above, except for families affected by HD where only young people 16 years and above could be interviewed.

- Children were only included in the interviews where parents confirmed that they had personally explained to the child about the genetic condition and its risks, and they were willing to answer any questions the interview may raise for the child.

- Definition of a family member according to Metcalfe et al (2008).

children learned about the genetic condition and genetic risk; how much they knew and understood; the level of openness; and the shared language used to describe the genetic condition, genetic risk and associated morbidity and mortality.

Throughout all stages of the analysis from fieldwork to coding, observations were used to develop a series of grounded theory questions (related to the research questions and to inductive ideas) that were used to examine the data. Each researcher examined data specific to two genetic conditions on the basis of grounded theory questions and noted any other additional observations including any negative cases. A second researcher randomly reviewed the analyses for consistency and negative cases. All three researchers discussed any disputes until consensus was reached. Finally, the findings from the family groups for each of the six conditions were compared for consensus and difference using a constant comparative analysis ${ }^{17}$ to identify the overall outcomes. The findings are reported in overarching thematic headings, which reflect the grounded theory questions that tested the data. ${ }^{17}$

\section{FINDINGS}

A total of 33 families were interviewed. The demographic profile of participants and their families is provided (Table 2). Families were recruited from across England and Wales but specific regional and 
other information that may make families identifiable to each other or to health professionals has been omitted to protect confidentiality.

Across all genetic conditions, many similarities were observed, and exceptions between conditions are indicated in the findings by denoting which conditions the comment is referring to.

When the transcripts of all members of a family were reviewed together, there was usually a strong level of consistency between reports about what and when children and young people had been told about a genetic condition and its risks. There was often a shared narrative about the condition and its effects on the family, and parents' understanding and views were often reflected in the explanations and descriptions given by their children. In families in which children had a better understanding and more insight, parents had usually discussed the condition throughout childhood, often as part of the family story.

Parents, children and most young people thought parents should be the main people to provide genetic risk information because they understood their children best. However, young people thought that health professionals should provide guidance and advice to parents. Over half of the young people also wanted information directly from health professionals, preferably ones who understood the contemporary issues faced at school, college and the transitions they faced at this developmental stage.

\section{Roles in communication}

Mothers were usually the key person in the family who shared genetic risk information. Some fathers took on this role as key informant or shared it with the mother, but children often described fathers as too angry or too upset to talk. Although some parents took shared decisions on talking to the children about the genetic condition, there were also equal numbers who did not discuss it with each other, or, if they did, they disagreed on the best course of action.

'... absolutely not. My dad went "La la la under the sea." Anything to do with HD that was it, switched off ... he couldn't cope with it I don't think ...'

Young person 15-17 years at risk from HD

Siblings rarely discussed the genetic condition or its risk with each other. Most communication took place between an individual child and their parent(s), whom they trusted above any other information source until they reached 15-17 years of age. Parents often recalled talking to their older children for the first time but many overlooked talking to their younger, unaffected children. Parents assumed that because the younger children witnessed the effects of the condition in the family every day, they automatically knew what was happening. Children did not talk to their parents' new partners about the condition but saw this person as a source of support for their parent (Figure 1).

'well he (younger sibling) doesn't hasn't said that he knows ... we haven't spoken to him as such, have we? ... he's just aware' Parent - Older child affected by DMD

Making decisions about the sharing of genetic risk information Across families, parents differed in deciding when and how they talked to their children about a genetic condition. Decisions were not usually related to their child's cognitive development but were more dependent on the morbidity of the genetic condition and whether it was lifelimiting. Only a small number of parents expressed a view that their child(ren) had a moral and ethical right to know about a genetic condition affecting their family.

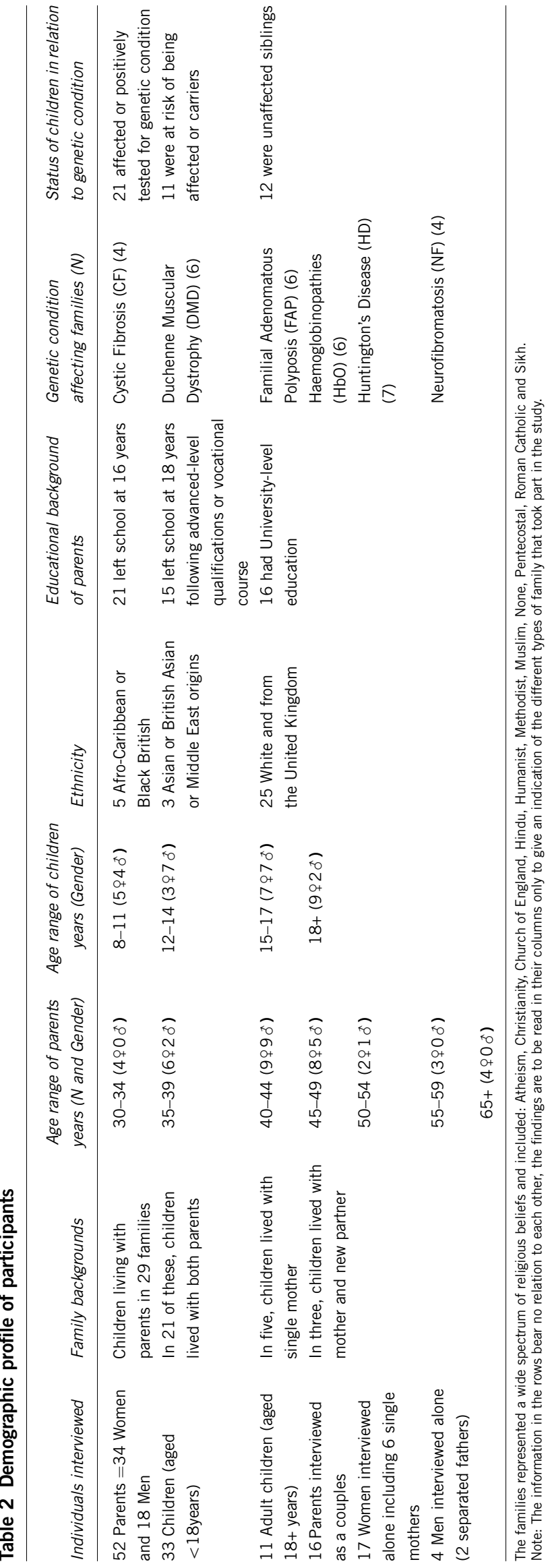




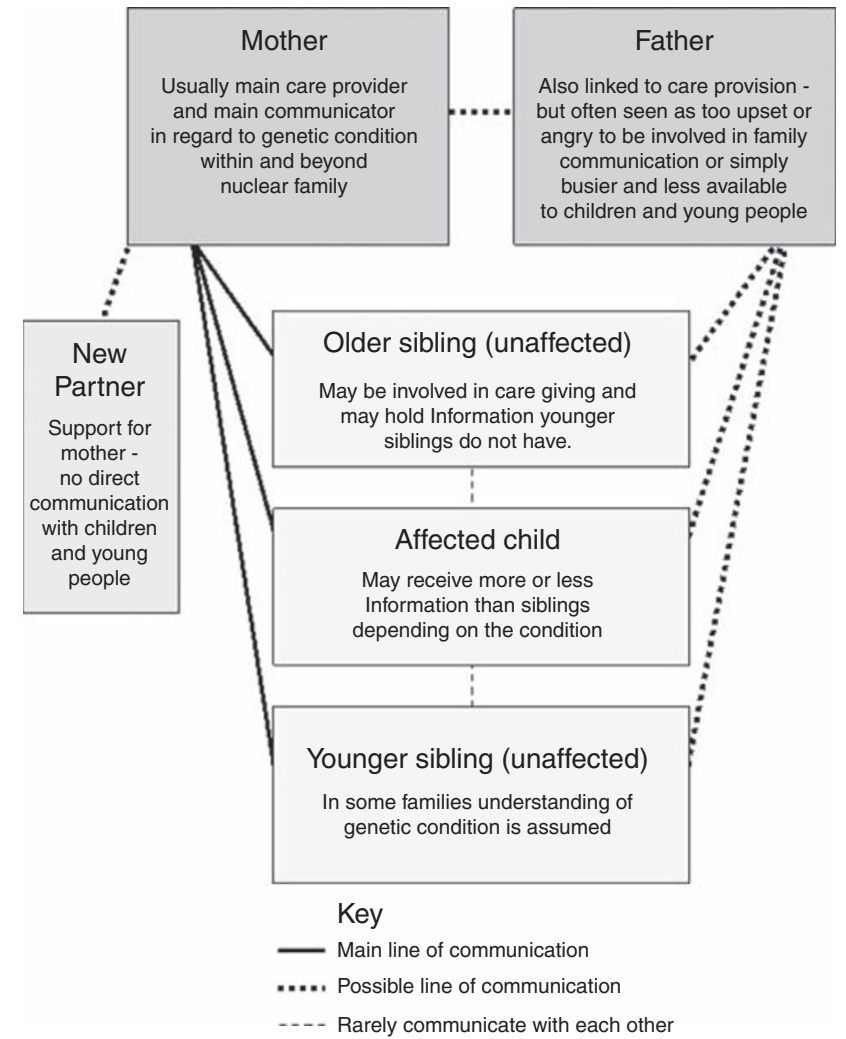

Figure 1 Family roles in the communication of genetic risk information.

Delaying or choosing the right time to talk to children about a genetic condition was often very distressing, and parents worried whether they were making the right decision. Most delayed discussions for as long as possible until a particular event, either internal or external to the family, initiated the need to discuss the condition. In contrast, most children and young people said that they had been aware at some level of the condition being in their family from a young age (usually by around 8 years) and wanted to be able to discuss it and understand what was happening in their family from then.

'I might be a bit angry if they didn't tell me because I would just want to know, so I don't think there is anything to hide really when you have got a disease, you have got a disease really, so but no I don't think there should be any secrets'

Young person 15-17 years of age, CF - affected

A number of factors often compromised the capability of parents to discuss genetic risk. These were related to one or more of the following, depending on the genetic condition and stage of disease progression: shock at diagnosis, which prevented parental discussion; guilt and fears before and after genetic testing; increased emotional and physical care giving; and experiences of grief and bereavement. A second article, currently in preparation, will expand on these factors in detail.

\section{How and what children are told}

All children, whether affected, at risk or unaffected, showed a high level of insight into how they learnt about the condition. Children said that they wanted small amounts of information at a time and to be able to discuss what was happening in their families with their parents. Children and young people reflecting retrospectively on their experience of learning about a genetic condition and its risks said that they came to learn and understand about the condition and its implications quite slowly. It took time for them to become aware of the risks, either to themselves or to other family members, and most children and young people said that they did not spend time repeatedly thinking about it once they had initially learnt about the risks.

Information given in the gradual way that children preferred increased their understanding over time, and gave them insight without the shock of learning about the condition and its implications all at once. Parents and young people said that receiving information as younger children was less shocking; moreover, because they learnt gradually as they grew up, it made new information and its implications easier to cope with. This lack of shock for younger children probably occurred because they had less insight and fewer experiences to draw on to recognise the fuller implications, unlike the young people who pieced information together very quickly to ask very challenging questions when they were not always prepared for the answers.

It was important to go at the child's pace, as information that was too graphic or went beyond what the child asked could stop them wanting to discuss the condition further. However, this was not achieved simply by waiting for children to ask questions, which parents often did. The lack of acknowledgement of the genetic condition by parents inhibited children aged 8-11 years onwards from asking questions about it because they thought it would upset their parents. Parents therefore had to make it clear to their child that they were happy to be asked questions. They also reported needing to check what their child knew already and correct misperceptions that frequently occurred, especially from overheard conversations.

'She (Mum) talked to me about why I should tell people if they ask me, erm sometimes I realise that it helps, erm but if she didn't ask me if anything's wrong then I wouldn't have, I wouldn't have mentioned it to her'

Sibling (8-11 years old) of a child with NF.

Children and young people thought that less formal discussions were the best, and they liked to discuss the genetic condition in situations in which they were also doing other things alongside their parent(s), such as preparing a meal, gardening or riding in the car. In some families there was a 'story' about the condition and parents told their children how they had learnt about the condition and had learned to cope with its effects. Parents thought that this taught children about coping with the condition, offered opportunities to talk and allowed different family members insight into each others' experiences and feelings. For some it was also an opportunity for children to look to parents or older siblings as role models.

'... me and my mum would erm, in the mornings me and my mum we're sort of people who get up first and so we would sort of just sit down by the sofa, like one of us would be on the computer and just sort of talking and, you know, it (HD) would come into the conversation ....'

Young person, 15-17 years of age, at risk of HD

Many parents said that they were completely open to discussing with their children, but further discussion revealed that this often meant answering questions as they arose. Many also talked at a different time in the interview about protecting children from certain aspects of the condition or risk until they needed to know about it. Most children and young people recognised these limitations, and when talking 
Understanding of genetic condition and risks

\begin{tabular}{|c|c|c|c|c|}
\hline $\begin{array}{l}\text { Children began to notice } \\
\text { and question visible } \\
\text { difference and some } \\
\text { asked if they were likely } \\
\text { to be affected in the } \\
\text { same way as what they } \\
\text { observed. Some } \\
\text { understood that the } \\
\text { condition was a result of } \\
\text { the biological } \\
\text { relationship between } \\
\text { parents and child in the } \\
\text { same way as eye } \\
\text { colour. }\end{array}$ & $\begin{array}{l}\text { Children understood } \\
\text { the condition in terms of } \\
\text { what they could see } \\
\text { and how it currently } \\
\text { affects their daily lives. } \\
\text { Most understood the } \\
\text { notion of hereditary in } \\
\text { terms of the condition } \\
\text { being passed down } \\
\text { through the family but } \\
\text { had no idea of } \\
\text { hereditary patterns. }\end{array}$ & $\begin{array}{l}\text { Children began to } \\
\text { understand more about } \\
\text { the condition in terms of } \\
\text { expected future symptoms } \\
\text { and about mortality. Most } \\
\text { understood hereditary in } \\
\text { terms of their relationship } \\
\text { to their parent(s) but not to } \\
\text { their future children. Most } \\
\text { use genetic language but } \\
\text { without an underlying } \\
\text { understanding, and they } \\
\text { could not describe } \\
\text { hereditary patterns } \\
\text { accurately or quantify risk. }\end{array}$ & $\begin{array}{l}\text { Young people understood } \\
\text { that they may carry a gene } \\
\text { that could or would affect } \\
\text { their health. They had a } \\
\text { clearer understanding of } \\
\text { mortality although still not } \\
\text { always the stages of } \\
\text { progression. They were } \\
\text { more able to describe } \\
\text { hereditary patterns and } \\
\text { began to realise the } \\
\text { implications for their own } \\
\text { future children. }\end{array}$ & $\begin{array}{l}\text { Young adults began to } \\
\text { understand the wider } \\
\text { implications of the } \\
\text { condition and relate it } \\
\text { more to themselves. } \\
\text { They realised how it } \\
\text { might influence their } \\
\text { career choices and } \\
\text { personal relationships } \\
\text { and how their decisions } \\
\text { relating to genetic testing } \\
\text { had impact on other } \\
\text { family members. }\end{array}$ \\
\hline Up to 7 years & 8 - 11 years & 12 - 14 years & 15 - 17 years & 18 years plus \\
\hline $\begin{array}{l}\text { Children seemed to } \\
\text { accept information at a } \\
\text { relatively superficial } \\
\text { level. There were some } \\
\text { behavioural problems or } \\
\text { signs of stress when } \\
\text { they were not given } \\
\text { information in difficult } \\
\text { family situations. }\end{array}$ & $\begin{array}{l}\text { Children continued to } \\
\text { accept information at a } \\
\text { relatively superficial } \\
\text { level and looked for } \\
\text { positives and did not let } \\
\text { the condition become } \\
\text { the central focus of } \\
\text { their lives. }\end{array}$ & $\begin{array}{l}\text { A period of rebellion for } \\
\text { some children who } \\
\text { became angry and } \\
\text { questioned 'why me?' } \\
\text { Some children challenged } \\
\text { treatments and routines. }\end{array}$ & $\begin{array}{l}\text { Young people reported } \\
\text { upset and shock as they } \\
\text { better understood the } \\
\text { mortality, responded to } \\
\text { test results or faced } \\
\text { surgery. However they } \\
\text { looked for positives and } \\
\text { did not let the condition } \\
\text { monopolise their life. }\end{array}$ & $\begin{array}{l}\text { The most difficult time } \\
\text { emotionally. Young } \\
\text { adults were coming to } \\
\text { terms with the } \\
\text { implications of the } \\
\text { condition at a time when } \\
\text { so many other important } \\
\text { life decisions and } \\
\text { choices are being made. }\end{array}$ \\
\hline
\end{tabular}

Timeline showing the observed changes with age of children and young peoples' understanding of the genetic condition and genetic risk, and their emotional responses to information if they learn new information in this age category.

Figure 2 Children's developing understanding and response to genetic risk.

about the level of their parents' openness qualified this with adjectives such as 'quite' or 'fairly'.

The affected child was usually given more information than siblings (CF, FAP, HbO, NF). However, if the condition was life-limiting and the child likely to die during adolescence, affected children were given limited information but their older siblings were told more about the outcomes, which they were expected to keep secret (DMD). Overall, parents' and children's discussions on genetic risk intertwined with the communication about the management of the genetic condition. This may explain why many children and young people often struggled to explain what they knew and understood about the genetic risks separately from the knowledge and discussion about the genetic condition and its day-to-day management.

Children's understanding of genetic risk and inheritance patterns On the basis of the self-reports of children and observations made by parents, patterns emerged in the understanding and reactions of children and young people during different stages of their childhood. This included those affected, those at risk and unaffected children (Figure 2). However, some differences in knowledge were identified across conditions and between inheritance patterns.

The dominant pattern of inheritance was easier for children to understand than the recessive or X-linked patterns but it was also accompanied by the most misconceptions. Children often thought that $50 \%$ risk meant that one of two children would be affected. Even adult children who knew this was not the case said it was difficult not to think in this way. Both parents and young people looked for phenotypic traits of a genetic condition in family members and sometimes thought that children who were most similar to an affected parent in personality or looks were more likely to inherit the condition.

In families with dominant conditions (HD, FAP, NF) children from the age of 10-11 years upwards understood that the condition was 'passed down' through their families, with some using the word 'inherited'. Most knew it had something to do with genes and sometimes talked about chromosomes and DNA. In instances in which the condition did not manifest until adulthood or adolescence (HD and FAP) it could be more difficult for children to conceptualise risk in terms of how the condition was going to affect their future lives.

\section{' born with it, something to do with my DNA when I was being made'}

Child 8-11 years of age, $\mathrm{HbO}$

Young people usually understood the risks for themselves during teenage years (around 12-15 years of age), but were usually 15-17 years old before they realised the reproductive implications. At this age some were also vaguely aware of possible interventions, such as in vitro fertilisation, that would be available to them to prevent their own future children being affected. Across the age range, children and young people talked about a '50:50' chance of inheriting the affected gene but only a few young people aged $12-15$ years and those aged 16 or older used the word 'dominant' to describe the genetic risk appropriately in the relevant conditions. With FAP, affected young people had a more detailed knowledge of dominant inheritance than unaffected siblings, usually because parents chose not to discuss risk information until after children had received a positive gene test.

'Erm I think the FAP comes from like other people's DNA ... and it goes, and goes through the family sometimes.'

Young person 12-14 years FAP - affected

Very few young people could explain recessive inheritance patterns accurately. Children and young people affected by recessive conditions (CF or $\mathrm{HbO}$ ) usually knew there was a risk to their potential children, 
although they did not understand its details. Some affected (CF or $\mathrm{HbO}$ ) girls knew that pregnancy would present some risks to their own health, and this was more meaningful to them than concerns about the genetic risk for their future children. Siblings at risk of carrier status who were younger than the affected child had been tested at birth but did not necessarily understand what this meant. Siblings who had not been tested did not understand the risk until they were about 16 years old and had been told before testing or when parents thought they might begin sexual relationships. When young people knew that they were or could be carriers of a recessive condition, they had little idea of population risk, and thus the likelihood of them having a child with another carrier.

In families affected by DMD, girls up to the age of 16 years did not understand the risks to their potential children. Children affected by DMD generally knew little about the condition, and heredity and genetic risk had not been discussed with them.

\section{Children's emotional response to genetic risk}

In families where parents treated communication about the genetic condition and its risks as an ongoing process throughout childhood, children and young people had greater insight and appeared to cope well with the condition and their increasing knowledge of associated risk. By contrast, families who had initially tried to keep risk information secret later viewed a lack of knowledge as having led to increased stress and negative emotional experiences for children, as well as for parents.

'It wasn't ooh boo hoo Mummy's poorly, it was a relief cause she understood why Mummy was the way, she had been treating her the way she was...'

Parent of child $<8$ years old - Partner had HD

In cases where communication was or had been less open, children struggled to understand what was happening and parents said they had observed signs of stress, such as children and young people becoming withdrawn and easily upset. Many young people said that they had felt better when they knew about and understood the implications of the condition and its risks. Young people often said that they had felt scared about the risk of inheriting something they did not fully understand and they had experienced problems with self-esteem. Some individuals thought that this may have been a contributory factor to them being bullied or causing self-harm.

In some families, parents encouraged and supported young people to make their own decisions about treatments, genetic testing and care provision. This appeared to encourage young people to discuss information and their thoughts about the genetic condition with their parents and usually to follow their advice. In contrast, we observed that young people did not discuss the genetic condition and their concerns with parents who made decisions and took a more authoritative role.

\section{DISCUSSION}

This is the largest study to date that explores the sensitive issues surrounding communication about genetic risk between parents, children and siblings. It has taken into consideration the views and experiences of families from six different genetic conditions that vary in inheritance pattern, age at onset, morbidity and life expectancy. Because of differences in these factors, the detailed content of family discussions varied slightly between the genetic conditions; however, the manner in which children learnt, their level of insight and understanding and the emotional impact of the knowledge gained were similar across each age range for each of the six conditions.

All children and young people valued being able to discuss genetic conditions affecting their family. Gradually learning about the condition as they grew up helped them cope and come to terms with the risk either to themselves or to other family members, including their own future offspring, irrespective of the disease outcomes, showing that assimilation of genetic risk information is a process rather than a single act. ${ }^{18}$

In cases where children had not always received explanations from their parents about a genetic condition, this had caused considerable strain on the individuals, parents and children, and on their relationships with each other and with their wider social networks. Once family communication became more open, this helped to re-establish understanding and a shared reality that enabled parents and children to support each other and cope better.

Most parents found deciding how and when to talk to their children about the genetic condition a distressing and major issue in family life. Despite being encouraged to talk to their children about the genetic condition by health professionals, most parents or children were unable to access appropriate advice and support at different developmental stages. However, this reflected the limited support available generally for these families, who often experienced other problems and issues related to their experiences of the genetic condition. A future study will explore this in more detail.

Children and young people, irrespective of their risk status, also highlighted their need for opportunities to meet with a health or social care professional with whom they could discuss the implications of genetic risk. Many young people were only just beginning to realise and understand the implications of genetic risk and the possibility of a carrier status when they were having genetic tests carried out. This raises serious ethical questions about how much the young people involved really understand when and after they have consented to the tests, and may indicate a need for further advice and guidance on the genetic testing of children. ${ }^{19}$

Young people often had difficulty understanding genetic risk information in terms of risk statistics and probability, and often relied on subjective judgments such as shared family phenotype features. Often this reflected parents' views but also characterises how lay people often view heredity ${ }^{20}$ and the well-documented difficulties many people face with understanding risk probabilities. ${ }^{21}$ All age groups of children and young people have difficulty in understanding probability terms, and younger adolescents (10 to 15 years) particularly have difficulty distinguishing between 'probably' and 'possibly. ${ }^{22,23}$ Probability information or risk percentages presented as a pie $\operatorname{chart}^{23}$ are the most effective method to assist children's understanding. Therefore, on the basis of this evidence and the findings presented, more effective genetic risk communication tools are required to aid parents and health professionals in providing better explanations.

Open family communication underpins the cohesion of families, and improves family members' commitment to long-term care of a parent or sibling. ${ }^{5,6}$ Strong and supportive families have the ability to transform both children's and parents' lives, and help them cope with illness, the risks involved and the care provision that may be needed. Therefore, the care of the family needs to go beyond preparing for genetic testing or carrying out treatments for the individual affected by the genetic condition. There is a need for greater family-centred care to support parents in advising and helping them to manage the condition while maintaining pivotal family relationships.

Supporting better family communication is likely to lead to better health outcomes for all family members. Greater family-centred care 
from health professionals will help family members cope and adjust to genetic risk information. This may be a role for a family support worker within existing professional groups. ${ }^{24}$ Such a worker could provide advice and guidance to parents on family communication about genetic risk communication, give young people the further information they require and generally support the family dynamics in managing and coping with the genetic condition.

The study does not allow us to know the generalisability of findings to the wider population of families affected by these and other genetic conditions. Future survey studies are required to find out the generalisability and test our theories further. In addition, the recruitment of these families via support groups is a potential bias. However, others have suggested that the majority of parents in families affected by genetic conditions share the experiences we have outlined. ${ }^{25}$ Further studies are therefore required to establish the prevalence of the problems that the parents and children identified, and to develop and evaluate interventions and resources to assist parents in talking to their children about genetic risk information.

\section{CONFLICT OF INTEREST}

The authors declare no conflict of interest.

\section{ACKNOWLEDGEMENTS}

We thank the parents, children and young people for participating in this study. We appreciate the willingness of these families to share their experiences with us so that we are able to learn from them what works well and what does not. We also acknowledge the invaluable contribution of advisory and steering groups. The Department of Health, England, funded the study and the views expressed do not necessarily reflect those of this Authority.

1 Holt K: What Do We Tell the Children? Contrasting the Disclosure Choices of Two HD Families Regarding Risk Status and Predictive Genetic Testing. J Genet Counseling 2006; 15: 253-265.

2 Gallo AM, Angst D, Knafl KA, Hadley E, Smith C: Parents sharing information with their children about genetic conditions. J Pediatr Health Care 2005; 19: 267-275.

3 Tercyak KP, Peshkin BN, Streisand R, Brogan BM, Lerman C: Psychological issues among children of hereditary breast cancer gene (BRCA1/2) testing participants. Psychooncology 2002; 10: 336-346.
4 Fanos JH, Puck JM: Family pictures: growing up with a brother with X-linked severe combined immunodeficiency. Am J Med Genet 2001; 98: 57-63.

5 Canam C: Coping with feelings: chronically ill children and their families. Nursing Papers: Perspect Nurs 1987; 19: 9-21.

6 McConkie-Rosell A, Heise EM, Spiridigliozzi GA: Genetic Risk Communication: experiences of Adolescent Girls and Young Women from Families with Fragile $X$ Syndrome. J Genet Counselling 2009; 18: 313-325.

7 Fanos JH, Davis J, Puck JM: Sib understanding of genetics and attitudes toward carrier testing for X-linked severe combined immunodeficiency. Am J Med Genet Part A 2001; 98: 46-56.

8 Sobel S, Cowan CB: Ambigious loss and disenfranchised grief: the impact of DNA predictive testing on the family as a system. Fam Process 2003; 42: 47-57.

9 Sobel S, Cowan CB: Impact of genetic testing for Huntingtons Disease on the family system. Am J Med Genet 2000; 90: 49-59.

10 Metcalfe A, Coad J, Plumridge G, Gill P, Farndon P: Family communication between children and their parents about inherited genetic conditions: a meta-synthesis of the research. Eur J Hum Genet 2008; 16: 1193-2000.

11 Segrin C, Flora J: Family Communication. New Jersey: Lawrence Erlbaum Associates, 2005.

12 Blumer H: Symbolic Interactionism: Perspective and Method. California: University of California Press, 1969.

13 Bandura A: Social Learning Theory. Upper Saddle River, NJ: Prentice Hall, 1977.

14 Coad J, Plumridge G, Metcalfe A: Developing art-based techniques for eliciting children and young people's views about their family communication in genetic conditions. Nurse Researcher 2009; 16: 56-64.

15 O'Kane C: The Development of Participatory Techniques Chapter 7; in: Christerson P and James A (eds): Research with Children: Perspectives and practices. London: Falmer Press, 2000.

16 Mauthner M: Methodological Aspects of Collecting Data from Children. Child Soci 1997; 11: 16-28.

17 Corbin J, Strauss A: Basics of Qualitative Research. Thousand Oaks, CA: Sage Publications, 2008.

18 Gaff CL, Clarke AJ, Atkinson P et al: Process and outcome in communication of genetic information within families: a systematic review. Eur J Hum Genet 2007; 15: 999-1011.

19 Borry P, Evers-Kiebooms G, Cornel MC, Clarke A, Dierickx K: On behalf of the Public and Professional Policy Committee (PPPC) of the European Society of Human Genetics (ESHG). Eur J Hum Genet 2009; 17: 711-719.

20 Walter F, Emery J: Coming down the line Patients' understanding of their family history of common chronic diseases. Ann Fam Med 2005; 3: 405-410.

21 Etchegary $\mathrm{H}$, Perrier C: Information processing in the context of genetic risk: implications for genetic risk communication. J Genet Counselling 2007; 16: 419-432.

22 Biehl M, Halpern-Felsher BL: Adolescents' and adults' understanding of probability expressions. J Adolesc Health 2001; 28: 30-35.

23 Ulph F, Townsend E, Glazebrook C: How should risk be communicated to children? A cross-sectional study comparing different formats of probability information. BMC Med inform decis making 2009; 9: 26.

24 Clarke A, Richards M, Kerzin-Storrar L et al: Genetic professionals reports of nondisclosure of genetic risk information within families. Eur J Hum Genet 2005; 13: 556-562.

25 Biesecker B, Erby L: Adaptation to living with a genetic condition or risk: a mini-review. Clin Genet 2008; 74: 401-407. 